\title{
O ESTUDO DE SABERES PROFISSIONAIS NA PERSPECTIVA ETNOGRÁFICA: CONTRIBUICÕ̃ES TEÓRICO-METODOLÓGICAS
}

Marise Nogueira Ramos*

RESUMO: O artigo discute a contribuição teórico-metodológica da etnografia para o estudo dos saberes profissionais. Defende o não abandono das determinações estruturais nessa perspectiva de análise, situando categorias do método histórico-dialético como necessárias para a reconstrução da relação entre singularidades e particularidades dos grupos profissionais e a totalidade social. Para isso, apresenta o conceito de saber profissional, relacionando-o com os conceitos de cultura e experiência, seguido de características e princípios da etnografia profissional, chegando a elementos práticos da pesquisa etnográfica. As considerações finais esclarecem que estudos sobre experiência, cultura e saberes profissionais permitem compreender sua natureza fenomênica e captar mediações da relação entre trabalho e educação, de modo a ver em que medida, ao se constituírem como grupos profissionais, os trabalhadores potencializam sua organização como sujeitos de classe.

Palavras-chave: Saber profissional. Cultura profissional. Etnografia profissional.

\footnotetext{
* Doutora em Educação pela Universidade Federal Fluminense (UFF); Professora da Faculdade de Educação da Universidade Estadual do Rio de Janeiro (UERJ) e dos Programas de Pós-Graduação em Políticas Públicas e Formação Humana (PPFH) da Universidade Estadual do Rio de Janeiro (UERJ) e em Educação Profissional em Saúde (EPSJV) da Fundação Oswaldo Cruz (FIOCRUZ). Email: ramosmn@ gmail.com
} 


\title{
THE STUDY OF PROFESSIONAL EXPERTISE IN AN ETHNOGRAPHIC PERSPECTIVE: THEORETICAL-METHODOLOGICAL CONTRIBUTIONS
}

\begin{abstract}
S: The article discusses the theoretical and methodological contribution of ethnography for the studies of professional expertise. The article defends also the non-abandonment of structural determinations in that perspective of analysis, situating categories of historical and pedagogical methods as a necessity for the reconstruction of the uniqueness of the relationship between professional groups and social totality. In order to do that, this report depicts the concept of professional knowledge related to the concepts of culture and experience, followed by features and principles of professional ethnography, reaching practical elements of ethnographic researching. The final considerations explain that studies on experience, culture and ethnographical and professional expertise motivate the understanding of their phenomenological nature and the understanding of mediations in relation to work and education, in order to see to what extension the groups forming themselves as professional workers empower their organization as actors of class.
\end{abstract}

Keywords: Professional Expertise. Professional Culture. Professional Ethnography.

\section{INTRODUCุ̃̃O}

Este artigo discute a possível contribuição da abordagem teórico-metodológica da etnografia do conhecimento profissional desenvolvida por Caria (2011; 2010; 2008; 2007; 2005; 2002; 2000), com o intuito de se articular um referencial sobre saberes profissionais, construir instrumentos de pesquisa empírica e desenvolver métodos de análise de dados sobre saberes profissionais.

Nossa proposta reafirma categorias fundamentais do materialismo histórico-dialético - totalidade, historicidade e contradição - como referência epistemológica, pois o propósito de penetrar em planos ainda pouco investigados na área Trabalho e Educação e em seu recorte da Educação Profissional não se limita a descrever singularidades do comportamento humano ou particularidades de grupos sociais. Ao contrário, pensamos que a apreensão dos saberes de grupos profissionais pode nos ajudar a compreender dinâmicas e processos pelos quais os trabalhadores se afirmam como sujeitos das relações sociais de produção e, assim, resistem e elaboram formas de enfrentamento à dominação.

Não obstante, tivemos forte inspiração teórica em autores da sociologia que desenvolvem uma reflexão no âmbito das ciências 
cognitivas, a exemplo Quéré e Fornel (1999); Quéré e Schoch (1998), Coulter (1989; 2001) e Dodier (1993), com influência da fenomenologia social. Por um lado, não perdemos o posicionamento crítico diante dessas correntes, pois reconhecemos, com Minayo (1994, p. 24), que "as críticas a essas perspectivas enfatizam o empirismo e o subjetivismo dos investigadores que confundem o que percebem e a fala que ouvem com a verdade científica e o envolvimento emocional do pesquisador com seu campo de trabalho". Por outro lado, não negamos a contribuição dessas correntes para a construção do senso comum como objeto da sociologia. Em outras palavras, ao mesmo tempo em que nos atentamos para o problema de essas correntes diluírem o senso comum e a experiência humana numa microssociologia subjetivista, a exemplo do interacionismo simbólico de G. Mead e da abordagem da teatralização do mundo social de E. Goffman ${ }^{1}$, entendemos que a compreensão dos processos sociais não pode prescindir do estudo da experiência humana (THOMPSON, 1981).

Como veremos adiante, a perspectiva etnográfica que tomamos se exclui dessa linha porque abordamos a interação social sem perder o vínculo destas com relações sociais de poder de natureza estrutural. Assim, no estudo dos saberes profissionais compartilhados por um grupo, as interações são definidas como o processo de significação mútua e de negociação de poder no nível microssocial. Estas, porém, sofrem as determinações da estrutura social e podem ter implicações de natureza macrossocial, à medida que se estendem para perspectivas de organização e atuação éticopolítica no plano das relações sociais de produção.

Por esses motivos, nossa trajetória de pesquisa referenciada éticopolítica e epistemologicamente no materialismo histórico-dialético não impediu a articulação com a fenomenologia social, especialmente para depreendermos a dinâmica social no plano das interações e do senso comum, no qual cotidianamente se produzem experiências coletivas.

Nosso principal desafio teórico-metodológico na realização de estudos sob essa perspectiva é perceber possibilidades e limites de natureza epistemológica de se fazerem dialogar o referencial histórico-dialético com a etnografia. Cremos que esse desafio pode contribuir para o enfrentamento de algumas tensões teóricas do campo Trabalho e Educação no Brasil, especialmente vinculadas à relação entre as análises macroeconômicas e as estratégias de enfrentamento, pelos trabalhadores, da exploração nos processos de experiência humana (THOMPSON, 1981).

Consideramos, ainda, a contribuição que o avanço da compreensão dos saberes profissionais pode dar à elucidação 
científica sobre fundamentos, motivações e limites de produção de conhecimentos pelos trabalhadores na sua prática social. Tal contribuição poderá se desdobrar para o âmbito das políticas públicas de educação profissional, universo em que nossa experiência profissional e acadêmica vem se consolidando.

O contexto de elaboração desse problema teóricometodológico são nossas atuais questões de pesquisa, dirigidas a trabalhadores técnicos de nível médio, que assim sintetizamos: 1) Qual o significado dos conhecimentos científicos aprendidos na formação profissional para os trabalhadores técnicos nas situações concretas de trabalho?; 2) Como esses trabalhadores combinam seus saberes da experiência com os conhecimentos científicos, inclusive reconstruindo-os, no enfrentamento das situações concretas de trabalho?; 3) Poder-se-ia depreender uma vinculação entre a mobilização dos saberes dos trabalhadores no seu processo de trabalho e as experiências educacionais?

Percebemos o quanto essas questões envolvem conceitos e perspectivas teórico-metodológicas densas que buscávamos compreender/construir no lastro dos trabalhos em etnografia do conhecimento profissional. Uma primeira contradição que surge na apropriação dessa perspectiva teórico-metodológica está em que a maioria das pesquisas considera profissões as atividades que exigem formação em nível superior (CARIA, 2010, p. 2). Em nossos estudos, o que definimos como atividades profissionais são aquelas que tenham algum conhecimento científico como base, a serem aprendidos na educação formal, seja esta de nível superior ou médio.

É nesse segundo nível que se encontram os nossos sujeitos de pesquisa. Esses têm, pelo menos, as seguintes características. Primeiramente, sua formação não ocorre em nível superior, mas no ensino médio ou após este, mediante uma formação técnicoprofissionalizante. Em segundo lugar registra-se o fato de que muitos desses trabalhadores obtiveram antes a experiência prática no trabalho para, depois, realizarem a formação técnica. Eles desenvolvem seu trabalho com baixa autonomia e elevada subordinação ao profissional de nível superior, ainda que diferentes níveis de autonomia possam ser encontrados. Dessa forma, esses trabalhadores possuem baixo poder social e simbólico. Suas atividades têm por base o conhecimento científico que orienta procedimentos técnicos, mas o acesso a esse conhecimento de forma sistematizada foi delimitado pelo nível de ensino exigido, de modo que os conteúdos selecionados pelas escolas que os formam tendem a ser restritos àqueles considerados 
necessários a orientar bons procedimentos práticos (RAMOS, 2010). Suas interações na atividade profissional são, muitas vezes, restritas a um profissional de nível superior e ao usuário do serviço.

Mesmo com essa configuração, o conhecimento científico está presente na atividade de trabalho, seja explícita ou implicitamente; e os trabalhadores fazem algum uso deles. Tais usos sofrem influência de algumas determinações estruturais, tais como as condições de classe, as políticas de educação e as de educação profissional; e de relações de poder instauradas entre subalternos e superiores e entre pares de um mesmo contexto profissional.

Por essas razões, nos autorizamos a considerar tais trabalhadores como profissionais, devido ao pressuposto de que utilizam (algum) conhecimento científico no seu trabalho e que este se realiza em relação direta com usuários em espaços e tempos delimitados. A abrangência e a complexidade do conhecimento utilizado são definidas face ao lugar que ocupam na divisão social do trabalho.

\section{CONCEITUANDO O SABER PROFISSIONAL}

O esforço que nos levou a este ensaio foi o de articular um referencial teórico para a análise sociológica do conhecimento e dos saberes profissionais. Primeiramente, deve-se dizer que o conceito de saber profissional pressupõe o conhecimento em uso, e não somente enunciado. Nesse sentido, ele não se confunde nem com o conhecimento científico resultado de investigações e apreensões da realidade pelo trabalho de pesquisa, nem com os recortes e apropriações aplicadas deste último na forma de conhecimento técnico e tecnológico ou, ainda, com enunciados de ordem filosófica, jurídica ou equivalentes ${ }^{2}$.

É verdade que as profissões têm como fundamento e delimitação os conhecimentos científico, tecnológico, filosófico e jurídico voltados para a explicação de fenômenos, para a criação e o desenvolvimento de processos e produtos, para a resolução de problemas, e para a regulação da prática social, nas diversas áreas em que a sociedade situa e organiza historicamente suas necessidades e produções. Mas o enunciado ou a proposição desses conhecimentos não se tornam saberes profissionais imediatamente. O saber profissional é, essencialmente, o conhecimento em uso pelos sujeitos em interação, guiados por alguma motivação. Assim, o conhecimento científico não é o saber profissional, mas sim uma de suas fontes. A outra é a experiência prática dos sujeitos em interação social. 
Portanto, o saber profissional é produto de uma dualidade epistemológica - a ciência e a prática - e também de uma dualidade sociocognitiva representada pelas mentes pragmática e analítica (EVANS, 2008; 2009). Por essas razões, o saber profissional não constitui uma epistemologia, como, por exemplo, a da prática, posto não ser possível adotar-se um único critério para a sua validação, seja a eficácia, seja a coerência. O que o caracteriza é exatamente uma combinação variável desses critérios, muitas vezes defasados um do outro na realização da ação, mas compartilhada pelo grupo profissional, na forma muito mais de uma cultura do que de uma epistemologia.

Enunciamos aqui uma discordância da abordagem de Tardif (2000), para quem a epistemologia da prática profissional é o estudo do conjunto dos saberes utilizados realmente pelos profissionais em seu espaço de trabalho cotidiano para desempenhar todas as suas tarefas. Da mesma forma que não consideramos que os saberes profissionais formam uma epistemologia e sim uma cultura, entendemos que a construção dos saberes profissionais como objeto das Ciências Sociais não funda uma epistemologia específica; antes, essa construção busca na interdisciplinaridade uma perspectiva de análise.

Ao identificarmos essas dualidades, interessa-nos saber se as experiências podem ser reforçadoras de condutas pragmáticoutilitárias ou podem oportunizar uma articulação dialética entre teoria e prática que proporcione a análise e a deliberação conscientes na prática social. Tratar-se-ia, nesse caso, de vislumbrar a realização da possibilidade ontológica da práxis.

Não negamos a especificidade pragmática do trabalho profissional, pois ele visa a resultados que não advêm somente do conhecimento científico que fundamenta e delimita a profissão. Mas também não se reduz a automatismos cognitivos gerados e consolidados na experiência. O trabalho, e consequentemente o saber profissional, é um processo de transformação prática do conhecimento científico em que os critérios de coerência e eficácia assumem uma tensa relação mediada pela experiência e pela reflexividade profissional visando a resultados concretos.

Ao mesmo tempo, queremos desvincular tal especificidade do critério utilitário que correntes da epistemologia adotam para "validar" um conhecimento independentemente da possível coerência com a realidade que este procura conceituar (pragmáticoutilitário). Portanto, a especificidade pragmática do trabalho e do saber profissional não é o mesmo que praticismo ou utilitarismo, ainda que, por várias razões (epistemológicas, ideológicas, conjunturais, estruturais, etc.), possa ser reduzido a isso. 
No plano empírico, porém, temos que reconhecer a existência da dualidade dos saberes associada às relações de poder. A possibilidade de o trabalho profissional ser orientado pela articulação dialética entre teoria e prática não significa que esta ocorra sempre e necessariamente. Ao contrário, a história da epistemologia e da teoria social tem demonstrado os obstáculos sociais e culturais - muitos deles de ordem estrutural - que impedem essa articulação.

Apesar de essa posição se revelar como um ceticismo no plano estrutural, no âmbito das culturas profissionais, o autor acima referido toma resultados de estudos etnográficos realizados com grupos profissionais (FILIPE, 2008; GRANJA, 2008) como base da hipótese sociológica de que a possibilidade de articulação entre as duas epistemologias e as duas mentes - pragmática e analítica - se põe em função da relação entre cognição e poder no trabalho profissional. Essa hipotética associação, ao nível micro, permite evidenciar, no estudo dos grupos profissionais, a autonomia (ou o conflito latente) técnica, política e cultural do trabalho profissional nos contextos de interação social, em face de estruturas, instituições ou de outros grupos sociais com maior ou menor poder simbólico (CARIA, 2011).

É o fato de o trabalho profissional ser contextual e situacional que faz com as prescrições cognitivas e organizativas sejam específicas a elas. Por isso, a ação teria pouco a ver com a formação clara e distinta de representações, cálculos e inferências; ou com deliberações e tomadas de decisões somente racionais. O resultado social da forma situada do conhecimento profissional - a cognição na ação - mediada pela interação social é o saber profissional: "o incerto, o contingente e o complexo, que exigem o improviso e a percepção do risco em situação" (CARIA, 2010, p. 9). O saber profissional é a forma como os membros de um grupo profissional coordenam suas ações em situação com consciência prática; isto é, com um conhecimento tácito habitualmente utilizado no desenvolvimento de sequências de conduta (GIDDENS, 2000).

O estudo do saber profissional pode nos levar a "padrões de organização (em simultâneo práticos e simbólicos)" (CARIA, no prelo) ou a "padrões de coordenação da ação" dos membros de um grupo profissional, de modo a produzir conhecimento científico sobre o conhecimento profissional. Ao mesmo tempo, se esse estudo tem como referência as questões de poder que entram em jogo nas interações, poder-se-á avançar na tese de que as possibilidades de articulação entre as duas epistemologias - ciência e prática - e as duas mentes - analítica e pragmática 
- na constituição do saber profissional dependem da diminuição das desigualdades de poder entre os sujeitos em interação (entre membros de uma equipe técnica; entre equipe técnica e outros níveis da organização; entre sujeitos e estruturas sociais).

A recontextualização do conhecimento científico é somente uma dimensão do saber profissional, porém insuficiente para compreendê-lo como produto das interações sociais, pelo fato de pressupor o conhecimento científico como ponto de partida da reflexividade social, apenas pondo em evidência as relações estruturais de poder sobre os discursos (CARIA, 2010). Este, portanto, não é o nosso eixo de análise, pois buscamos valorizar a mobilização "horizontal" de conhecimentos em situações de trabalho profissional. Por isso, a etnografia profissional se constitui na opção metodológica de nossos estudos. Alguns de seus pressupostos e características serão abordados a seguir.

\section{ETNOGRAFIA PROFISSIONAL CRÍTICA: O ESTUDO DE INTERACִÕES SOCIAIS MEDIADAS POR RELAÇÕES DE PODER}

Explicitamos anteriormente que, no estudo dos saberes profissionais, entendemos a "interação como interpretação de expectativas mútuas em reciprocidade" (CARIA, 2002, p. 137) mediadas por relações de poder. Estas, por sua vez, trazem determinações de ordem estrutural, mas podem ser tencionadas em situações em que as interações extrapolam a construção de consensos. Do ponto de vista da fenomenologia social, as situações refletem necessariamente a estrutura do mundo social, o que justifica sua análise e a validade das generalizações que dela se podem extrair.

$\mathrm{Na}$ perspectiva do materialismo histórico-dialético, entretanto, a articulação entre os níveis microssociais das interações e a estrutura macrossocial das relações sociais de produção pode ser explicada pela categoria totalidade. Esta define a realidade como um todo estruturado, dialético, no qual ou do qual um fato qualquer (classe de fatos, conjunto de fatos) pode vir a ser racionalmente compreendido. Acumular todos os fatos não significa conhecer a realidade; e todos os fatos (reunidos em seu conjunto) não constituem, ainda, a totalidade (KOSIK, 1976). As situações e os objetos singulares podem ser conhecidos à luz de conceitos mais gerais ou universais, passando pelo tempo e o espaço onde ocorrem. Assim analisados, constituem-se como particularidades, campo de mediações históricas produzidas pela ação de sujeitos sociais. 
As pessoas que compartilham experiências equivalentes no âmbito de um grupo social tendem a compartilhar um conjunto de conhecimentos tácitos que mantêm o fluxo da interação. Estas podem ser orientadas pela busca do consenso, quando se tenta eliminar ou, pelo menos, atenuar as tensões que surgem da interpretação de expectativas. Normalmente se evita o conflito, ainda que sua possibilidade seja também inerente à interação. Porém, esse fato poderia interromper a interação, contrariando o sentido de sua existência. Nem o consenso, nem o conflito dão lugar ao "emergente", isto é, àquilo que pode ser origem de novos conhecimentos e novas regras.

O emergente só pode surgir quando as tensões não são eliminadas pelo consenso nem acirradas ao ponto de fazer irromper o conflito. $\mathrm{O}$ emergente tem como pressuposto a existência de constrangimentos e tensões que potencializam soluções no fluxo da interação. Ela corresponde ao improviso, ao situacional, que produz, inicialmente, aprendizagens implícitas, não representacionais; o tácito coletivo (COLLINS, 2010). Porém, elas podem ser organizadas como novas representações, consolidando-se como conhecimento explícito.

A emergência surge em interações que ocorrem em sistemas abertos, pois em sistemas fechados não há interesse pelo novo. É necessário que haja uma relativa, mas não substantiva, desigualdade de poder entre os sujeitos da interação (nos termos, por exemplo, em que Vygotsky define a zona de desenvolvimento proximal), de modo que o detentor de mais poder se disponha a perdê-lo e a submeter-se ao poder do outro. Essa é a racionalidade compreensiva. Trata-se de uma oposição, simultaneamente, à violência simbólica de Pierre Bourdieu e à simples negociação de significados da etnometodologia e do interacionismo simbólico.

Os grupos profissionais são exemplos da possibilidade de se criar relações desse tipo, pois se constituem por pessoas com diferentes trajetórias (que redundam em desigualdade de poder); identidades próximas (que as colocam em condições de interagirem); e que se dedicam à troca, cultivando a reflexividade. As interações realizadas nesses termos são produtoras do senso comum compartilhado pelo respectivo grupo, e não há, necessariamente, um objetivo explícito ou a busca de uma solução coletiva a guiar a interação. Assim se conforma a cultura profissional.

Pode-se, entretanto, passar do fluxo corrente da interação a sistematizações que promovem soluções coletivas, a exemplo de quando se busca preservar a identidade do grupo ou interferir, explicitamente, em um projeto institucional ou social. Nesse plano 
começam a se manifestar mediações entre o conhecimento tácito e o explícito; entre as interações e as relações sociais; entre as questões de poder presentes no universo micro das primeiras e as determinações históricas econômico-sociais das segundas.

Tais mediações podem ser vistas se admitirmos que, nas interações, agimos também em função de expectativas institucionais e sociais. No plano macrossocial, o sujeito com quem a pessoa interage é coletivo, é institucional. As expectativas e as respostas que se dão a elas determinam, em alguma medida, as condutas no nível microssocial, assim como estas podem se articular em interesses, projetos e ações comuns que acabam por organizar grupos sociais que passam a se constituir também como sujeitos coletivos, cujas práticas podem ultrapassar interações locais em direção a relações sociais de alianças e/ou conflitos com outros sujeitos coletivos. Em qualquer um desses casos, porém, a interação precisa enfrentar "quebra de expectativas", tensões, para que as ações reprodutoras se desestabilizem e se abram possibilidades criadoras com o emergente.

É verdade, porém, que a classe e os grupos sociais que detêm o poder econômico-político na sociedade não se dispõem a perdê-lo em nome da compreensão. Por isso, se procede aceitar que as consequências sociais da definição da realidade como construção social (BERGER, LUCKMAN, 1973) muitas vezes são irrelevantes no plano institucional ou estrutural de organização da sociedade (GOFFMAN, 1991).

Nesse plano, a desigualdade de poder é tanto estrutural quanto extrema e o princípio que acaba ordenando as relações é o da hegemonia - que implica a obtenção do consentimento ativo dos governados (GRAMSCI, 1991a) - e não o da compreensão. Porém, para Gramsci, a contra-hegemonia pressupõe transformações de ordem moral e intelectual, ao que associamos o conceito de "experiência transformada" de Thompson (1981).

Entendemos que esse tipo de transformação pode ocorrer também no plano das interações sociais, implicando a necessária valorização do senso comum. Isso nos parece corresponder ao que Caria enunciou como o projeto crítico da etnografia, especialmente a dos conhecimentos profissionais (ou simplesmente etnografia profissional) desenvolvida em sua perspectiva. Alerta o autor, porém, que essa possibilidade está vinculada ao cumprimento dos princípios compreensivos, o que impõe ao etnógrafo ser um bom tradutor da reflexividade interativa do grupo para gerar aliados ideológicos no seu interior. 
Para além de uma tomada de posição ético-política em relação à etnografia profissional, e de seus princípios que rompem com o objetivismo e o subjetivismo em Ciências Sociais, parecenos que o potencial crítico dessa abordagem advém, primeiro, do fato de ela considerar as desigualdades de poder nos processos de interação social; segundo, por estudar tais interações no âmbito de um grupo social delimitado no qual as práticas são construtoras de sentido e têm por referência tanto relações sociais mais vastas, quanto a reflexividade social de seus membros. Esse último fato impede que sejam vistas as determinações da estrutura social como independentes dessas práticas.

Esse tipo de delimitação cria a cultura profissional como seu objeto teórico que, no cotidiano, expressa a sobreposição de práticas sociais, identidades coletivas e reflexividade social (CARIA, 2011). A etnografia profissional crítica focaliza a cultura profissional nessa perspectiva por entender que a estrutura social não é um constructo independente das práticas sociais cotidianas. Ao mesmo tempo, não abandona as relações sociais de poder de natureza estrutural como referência. Por essa articulação entre dimensões macro e microssociais, procura-se seguir o que o historiador inglês Thompson (1981) incentiva: recolocar a agência humana na história, ainda que esta seja marcada por uma ambivalência crucial: "parte sujeitos parte objetos, agentes voluntários de nossas próprias determinações involuntárias" (THOMPSON, 1981, p. 101).

O conceito de experiência que esse mesmo historiador elabora pode nos ser útil na articulação entre essas duas dimensões da vida social. Para ele, a experiência - uma categoria imperfeita compreende a resposta mental e emocional, seja de um indivíduo ou de um grupo social, a muitos acontecimentos inter-relacionados ou a muitas repetições do mesmo tipo de acontecimento. A experiência não seria um nível muito inferior de pensamento que produziria um grosseiro senso comum. Ao contrário, ela é abordada como válida e efetiva, ainda que dentro de determinados limites: "o agricultor 'conhece' suas estações, o marinheiro 'conhece' seus mares, mas ambos permanecem mistificados em relação à monarquia e à cosmologia" (THOMPSON, 1981, p. 16).

Portanto, por mais espontânea que seja a experiência, ela nunca está desprovida de pensamento. A experiência "surge porque homens e mulheres (e não apenas filósofos) são racionais, e refletem sobre o que acontece a eles e ao seu mundo" (THOMPSON, 1981, p. 16), ou seja, todos os homens são filósofos (GRAMSCI, 1991b), 
mesmo que seu pensamento seja o mais simples e desagregado senso comum. Assim, a experiência está sempre acompanhada de um conhecimento mesmo que este seja de natureza tácita.

Assim, Thompson parece nos levar tanto ao princípio da reflexividade que usamos para teorizar sobre a cultura profissional, quanto para enunciar que a experiência vivida pode ser também percebida e modificada; e é esta que provoca pressão sobre todo o ser social. Portanto, encontramos aqui um sentido para se estudar o senso comum, o conhecimento prático, os saberes de grupos profissionais a partir de sua própria experiência, e não somente dos processos formais de aquisição do conhecimento científico: a sociedade produz os sujeitos e estes produzem sociedade, não só quando se organizam e lutam contra interesses antagônicos, mas quando produzem a si próprios na sua experiência social cotidiana.

\section{CARACTERÍSTICAS E PRINCÍPIOS DA ETNOGRAFIA PROFISSIONAL CRÍTICA}

O intento das etnografias profissionais é o de recolher dados de observação e de descrição de práticas e de interações sociais relativas a atividades de uma profissão e, portanto, a culturas profissionais, o que confere a esse recorte uma especificidade frente à tradição antropológica da etnografia (CARIA, 2000; 2005; 2011). Como atividade de uma profissão entende-se o que é feito e pensado pelos membros de um grupo profissional quando interagem entre si ou quando interagem por referência ao papel e ao estatuto social da profissão a que reconhecem pertencer. Esses sujeitos criam para si, no seu processo de socialização profissional, uma imagem e uma ideia da sua função social, a partir do que julgam os outros e esperam de si, sendo essa expectativa partilhada pelos membros da profissão.

Nas rotinas, nas categorizações, nas normas grupais e nos usos da escrita estão inscritos saberes que implicitamente apenas dependem dos membros do grupo, embora não sejam exclusivamente endógenos, em virtude de estarem misturados com conhecimentos, dispositivos e tecnologias produzidos nas relações sociais. As etnografias profissionais, portanto, não têm somente a pretensão de recensear os saberes de cada profissão, mas sim a de compreender e explicar, de modo comparado, a relação entre os conhecimentos que advêm da teoria e os que advêm da experiência, numa dada profissão. Essa relação se expressa através de interrogações tácitas que organizam/coordenam a ação coletiva em contextos e 
situações de trabalho quando os profissionais têm que responder a perturbações da sua atividade cotidiana.

A realização da etnografia profissional implica construir uma interação específica - a do etnógrafo com o grupo estudado mediada ela própria por relações de poder. De um lado há o poder do etnógrafo, que pode levar a interação aos termos necessários à investigação científica (o próprio fato de ser um investigador, com vínculos acadêmicos, expressa uma condição de poder). De outro há o poder daqueles que conhecem seu cotidiano e que podem falar sobre ele, permitindo, mais ou menos, o acesso do etnógrafo à sua realidade.

A racionalidade compreensiva, aqui, pressupõe que o etnógrafo se disponha a abdicar do seu poder (do seu etnocentrismo científico) em benefício de situações em que o conhecimento tácito dos sujeitos emerja sem que seja decodificado arbitrariamente por uma linguagem científica na qual esses sujeitos não se reconheçam e/ou que desqualifique os saberes prático-experienciais construídos no cotidiano. Os sujeitos investigados, por sua vez, também precisam se dispor a colocar seu poder em suspenso para que haja um fluxo na interação. Tal abdicação recíproca não supera as diferenças de poder entre ambos, mas não torna tais diferenças obstáculos para a investigação.

Podemos, então, caracterizar a etnografia profissional com base em alguns princípios, a saber: a) rompimento tanto com o objetivismo quanto com o subjetivismo em Ciências Sociais; b) consideração das desigualdades de poder nos processos de interação social; c) estudo de tais interações no âmbito de um grupo social delimitado no qual as práticas são construtoras de sentido e têm por referência tanto relações sociais mais vastas, quanto a reflexividade social de seus membros; d) em consequência, constituição da cultura como seu objeto teórico que, no cotidiano, expressa a sobreposição de práticas sociais, identidades coletivas e reflexividade social; e) compatibilização da teoria e da linguagem comum na construção do conhecimento científico.

A etnografia assim delineada visa entender a união indissociável realizada cotidianamente pelos sujeitos sociais entre fazeres e saberes e entre estes e as interpretações que fazem coletivamente dessas ocorrências, para poderem gerir os processos de socialização (definição e justificação de normas sociais), os processos de mudança social e os "disfuncionamentos" do grupo (comportamentos desviantes ou gestão de contradições e ambiguidades na divisão de tarefas ou relações com o exterior) (CARIA, 2000). Ao mesmo tempo, ao entendermos esses processos de socialização como constituidores de culturas 
profissionais, propomos captar elementos de identidade que poderiam transcender a delimitação do grupo profissional em direção à classe social trabalhadora. Em outras palavras, pensamos que a elucidação de elementos de negociação de poder entre sujeitos que interagem no interior de um grupo profissional realizada em benefício de sua identidade pode ajudar a revelar desigualdades de classe.

Para Thompson (1981), a classe se manifesta quando os sujeitos percebem que suas experiências isoladas são também coletivas. A classe não se faz só por referência a outra classe, mas também na relação dentro da classe. Por isso, podemos nos valer de seu pensamento para pensar a experiência não só de uma multidão de trabalhadores, mas também de grupos pequenos. O que vale é se a experiência é vivida e percebida como do grupo e não de indivíduos isolados. A experiência, em Thompson, tem ligação com a práxis, no que se refere à capacidade transformadora que ela carrega. E esta se realiza no plano do cotidiano, do senso comum, da cultura popular, lugares das contradições e das ambivalências.

As etnografias profissionais estão vinculadas às culturas profissionais, o que confere a esse recorte uma especificidade frente à tradição antropológica da etnografia. Essa perspectiva da etnografia se opõe, simultaneamente: a) à intervenção do investigador sobre o objeto a partir de um diferencial de poder conferido por essa condição; b) ao tratamento do senso comum partilhado por um grupo social como um resíduo face ao valor conferido ao conhecimento científico; c) à simples compreensão das interações sociais como negociação de significados; d) à recolha e ao tratamento de dados textuais com vista a encontrar padrões de organização dos discursos e das representações do mundo social dos quais os sujeitos são inconscientes ou nos quais eles não se reconhecem (CARIA, no prelo). Sobre esse último aspecto, vale dizer que não se trata da análise de discurso ou de representações sociais, mas sim de o etnógrafo tentar contribuir para a explicitação de conhecimentos dos sujeitos investigados por eles próprios (ajudá-los a saber que sabem).

\section{ELEMENTOS PRÁTICOS DAS ETNOGRAFIAS PROFISSIONAIS}

Para a consecução dos intentos das etnografias profissionais, é preciso que a metodologia de investigação procure obter dados sobre as atividades profissionais que, simultaneamente, se refiram a regularidades e a variações, em diversos aspectos. Primeiramente, 
as rotinas da atividade devem ser abordadas em termos das práticas e que todos os dias são realizadas (incluindo com quem, quando e onde), considerando tanto a parte planejada dessas práticas quanto a que varia de acordo com circunstâncias das pessoas. Também deve se ver o que dessa variação é salientada como situação imprevisível e como reação de ajustamento ao não esperado.

Procura-se captar, ao nível da linguagem cotidiana, o que é dito e repetido entre as pessoas do grupo profissional (também incluindo com quem, quando e onde). Uma parte dessa linguagem é técnica, isto é, típica dos protocolos de trabalho; mas é relevante perceber aquilo que introduz, ao nível da linguagem, ambiguidades (variação de sentido) no modo como as coisas são categorizadas. Por exemplo, pode-se atribuir o mesmo significado a coisas diferentes ou a mesma coisa pode ter significados diferentes em outros momentos. Dentre ambiguidades, há aquelas que podem indicar a tentativa de se obter consensos sobre o sentido das coisas, o que é muito importante para o estudo da cultura profissional.

Além disso, as censuras e sanções que ocorrem na interação (normas do grupo) devem ser vistas dando-se atenção ao que é descrito e considerado (incluindo com quem, quando e onde) como não fazendo parte da identidade do grupo. Finalmente, é válido também se observar o uso da escrita, isto é, objetos e suportes escritos (em papel ou digitais) que são continuada e repetidamente usados/produzidos (incluindo com quem, quando, onde e para quê), qual a sua origem e natureza (quem os produziu e/ou usou originalmente) (CARIA, 2011).

A definição do campo empírico deve considerar a possibilidade de acompanhamento do trabalho profissional, com a regularidade e pelo período que seja tanto viável quanto suficiente para a saturação do estar no campo. A permanência no campo visará à observação sob os pressupostos já apresentados, sendo, então, o etnógrafo a principal fonte de dados e o diário de campo, a principal ferramenta de registro, a ser utilizada, preferencialmente, após cada período da observação. A observação poderá ser guiada por um roteiro, mas de uma forma flexível, com prioridade para a sensibilidade do etnógrafo em seu "ser" e "estar" no campo.

O tratamento dos dados, por sua vez, é um momento da elaboração teórica sobre a informação empírica. Em nossa experiência temos utilizado a técnica de conteúdo de Bardin (2004) na perspectiva defendida por Rey (2002, p. 146), qual seja, “aberta, processual e construtiva e [que] não pretende reduzir o 
conteúdo a categorias concretas restritivas". O desafio está na construção de categorias que nos ajudem a organizar e sintetizar com sentido, fatos, momentos ou processos da realidade observada.

Casa-Nova (2009) explica que, ao longo da investigação por ela realizada e da sua narrativa produzida, procedeu à construção de categorias interpretativas e categorias conceptuais: as primeiras, resultando de um processo de interpretação dos dados; as segundas, resultando também de uma interpretação dos dados, mas tendo subjacente um processo de abstração mais complexo, mediante o qual se deu a produção de conceitos. O eixo de cruzamento analítico dessas categorias - interpretativas e conceptuais - seria, fundamentalmente, a síntese orientada pelas categorias do método histórico-dialético.

O trabalho etnográfico pode ser precedido de entrevistas, com o intuito de identificar elementos de trajetórias educacional e profissional, visando compreender motivações que permeiam a atuação profissional no contexto dado. Nesse caso, convém que as entrevistas sejam do tipo semiestruturadas ou semidiretivas, na qual existem perguntas previamente elaboradas para que não se percam de vista os objetivos que a orientam. Porém, a "conversa" deve ser mais guiada pelos objetivos que se têm em mente do que pela formalização das perguntas. É fundamental que as pessoas se ponham a falar, mas que também consigamos que sua fala se oriente para os nossos objetivos, sem que tenhamos, para isso, que invadir ou interceptar a fala dos sujeitos, com o risco de comprometer seu fluxo e, assim, perder esse meio como fonte de dados.

Podem ser necessárias e/ou úteis para se identificar sujeitos da pesquisa a serem entrevistados depois em profundidade e observados conforme os procedimentos etnográficos. Nesse tipo de entrevista, uma conotação mais aberta pode ser conveniente, pois essas não são iguais às entrevistas etnográficas, tendencialmente híbridas (fechada e aberta). Estas são geralmente desenvolvidas de modo informal durante (ou após) uma observação participante num dado local e fundamentam-se no quadro de uma epistemologia que serve ao método etnográfico. Quando possível, pode-se também fazer entrevistas etnográficas no sentido de consolidar e/ou validar as interpretações do etnógrafo e perceber o reconhecimento dessas interpretações pelos sujeitos observados.

Uma última questão refere-se à natureza da "observação participante" que caracteriza a etnografia. Tendemos a nos posicionar pelo viés do que Caria (2000) chama de "implicação periférica do investigador", posição semelhante assumida também por Neves 
(2008) e Casa-Nova (2009). A ideia de implicação vincula-se à perspectiva qualitativa e não positivista de investigação e nos remete à relação indissociável e contraditória entre sujeito e objeto. Porém, na etnografia, a implicação não se confunde com a submersão do investigador no local, resguardando-se "a distância analítica não desconexa do objeto" (LEVY3, 1985, citado por CARIA, 2000, p. 104). Também não é o mesmo que a investigação-ação, apesar de esta última igualmente pressupor relações de implicação. Ocorre que, enquanto a segunda tem os objetivos de intervenção-mudança como centrais, a primeira os tem como periférica.

Alerta aquele autor, entretanto, que os níveis de participação não são uma relação inversa da observação (mais observação, menos participação e vice-versa), pois a observação sem participação tende a abandonar a ideia de implicação, o que pode levar a um resvalo da investigação pelo viés positivista. Portanto, a presença prolongada no campo é sempre participação, pois condiciona, de algum modo, o comportamento dos outros, assim como o investigador também se vê influenciado pelos sujeitos observados. Dessa forma, a implicação periférica do etnógrafo nas relações do/com o grupo investigado significa alimentar um posicionamento que, ao mesmo tempo, não é neutro e não é tampouco invasivo face aos acontecimentos.

Essa perspectiva da observação-participação não significa a perda do potencial crítico da etnografia em benefício exclusivamente do potencial compreensivo. Um texto fidedigno à realidade do grupo investigado e que, por isso, não produz somente conhecimento sobre o grupo, mas que pode ser reconhecido e (re)apropriado pelo próprio grupo, é também um instrumento desse mesmo grupo para alargar seu poder, à medida que a etnografia seja uma espécie de inventário do seu "conformismo" (GRAMSCI, 1991b). Desse modo, o texto etnográfico torna-se, ele próprio, uma emergência produzida na interação, mas também sistematizado como um conhecimento que não é sobre o grupo, mas do próprio grupo. Por isso, um texto, que é também um instrumento do grupo para alargar seu poder com base no seu (novo) senso comum (CARIA, 2011).

\section{CONSIDERACְ̃̃ES FINAIS}

Procuramos apresentar uma abordagem teórico-metodológica para a investigação de saberes profissionais. Trata-se de uma tentativa de captar conhecimentos reais de trabalhadores, geralmente práticos, tácitos e próprios da experiência profissional. De alguma maneira, 
colocamo-nos o desafio de pensar o empírico, o local, o específico, os sujeitos e suas interações, sem perder a ligação com a totalidade social. Em outras palavras, ver a sociabilidade que se produz no conjunto das relações sociais, mas que também se produz e se expressa na singularidade das interações e na particularidade das culturas profissionais. Trata-se de um estudo que tem as categorias experiência e cultura como chaves para a compreensão da vida social. Nesse sentido, o pensamento de E. Thompson (1988; 1998; 1981; 2002) é-nos uma referência relevante.

Do ponto de vista teórico-metodológico, entendemos que as categorias experiência, cultura e saberes, porque passíveis de ser tratadas empírica e fenomenicamente em face de um dado objeto, podem nos mostrar singularidades de grupos sociais, enquanto conceitos como classe e consciência de classe sejam categorias das particularidades e da totalidade históricas das relações sociais de produção. A totalidade social poderia, então, ser compreendida pelas mediações que vinculam essas dimensões da realidade.

Assim, consideramos que a compreensão do objeto em sua manifestação empírica e fenomênica pode ser uma necessidade para que as mediações que vão para além desta não sejam meras deduções lógicas ou idealizadas. Parece-nos que o materialismo histórico-cultural defendido por Thompson não visa transcender imediatamente o fenômeno da vida social cotidiana em busca da sua essência. Ao contrário, reconhece que não se pode ir além do fenômeno sem se buscar compreendê-lo exaustivamente na sua manifestação empírica. Compreender o fenômeno na sua manifestação empírica parece-nos ser o projeto da fenomenologia, enquanto o do materialismo é tentar captar o que o fenômeno revela e, ao mesmo tempo, esconde. A orientação por esse segundo projeto não implica negar o primeiro, mas a partir deste reconhecer que o conhecimento que prescinde da realidade empírica ou que a transcende em nome de um sistema conceitual finito pode se reduzir ao teorismo, uma ponta do viés científico que no outro extremo se encontra com o seu oposto: o empirismo.

Concluímos, então, que nossos estudos sobre os saberes profissionais, além de nos permitir compreender sua natureza fenomênica e captar mediações no âmbito da relação entre trabalho e educação, podem nos ajudar a ver em que medida, ao se constituírem como grupos profissionais, eles potencializam sua organização como sujeitos de classe. Não obstante, ao colocarmos 
esse horizonte como possibilidade, não queremos que ele nos impeça de ver o empírico, o cotidiano, o comum.

Assumimos, finalmente, a etnografia do conhecimento profissional numa perspectiva crítica como a base teóricometodológica de nossas pesquisas sobre esse objeto, entendendo que o potencial crítico de seu projeto está no fato de esta entender que a estrutura social não é um constructo independente das práticas sociais cotidianas. Ao mesmo tempo, não abandona as relações sociais de poder de natureza estrutural como referência. Por essa articulação entre dimensões macro e microssociais, procura-se seguir o que o próprio Thompson incentiva: recolocar a agência humana na história, ainda que esta seja marcada por uma ambivalência crucial que nos faz, ao mesmo tempo, sujeitos e objetos; ou, dito de outro modo, produtores de nossa existência em meio à dualidade entre dimensões voluntárias da agência e outras involuntárias da estrutura.

\section{REFERÊNCIAS}

BARDIN, L. Análise de conteúdo. Lisboa: Edições 70, 2007. p. 23-41.

BERGER, P.; LUCKMANN, T. A construção social da realidade. Petrópolis: Vozes. 1973.

CASA-NOVA, M. J. Etnografia e produção de conhecimento. Reflexões críticas a partir de uma investigação com ciganos portugueses. Lisboa: Alto Comissariado para a Imigração e o Diálogo Intercultural, 2009.

CARIA, T. Poder e conhecimento no trabalho profissional baseado nas Ciências Humanas e Sociais no terceiro setor: dados preliminares do projeto SARTPRO. In: CARIA, T.; CARVALHO, T.; SANTIAGO, R. Grupos profissionais, profissionalismo e sociedade do conbecimento. Tendências, problemas e perspectivas. Porto: Edições Afrontamento. 2011. p. $59-80$.

. A mobilização de conhecimento em situação de trabalho profissional.

Versão revista e ampliada. In: FARTES, V.; ROSELI, M. Currículo, Formação e Saberes Profissionais. Bahia: EDUFBA, 2010. p.165-193.

O uso do método etnográfico no estudo do trabalho e do conhecimento profissionais. In: Leonor Torres \& José Palhares (orgs.). Metodologias qualitativas da investigação em educação e formação. Vila Nova de Famalicão: Húmus [no prelo].

O uso do conceito de cultura na investigação sobre profissões. Análise

Social, vol. XLIII (4. $\left.{ }^{\circ}\right), 749-773,2008$.

Itinerário de aprendizagens sobre a construção teórica do objecto saber.

Etnográfica; 11 (1): 215-250; 2007.

. (org.). Saber Profissional. Coimbra: Almedina, 2005.

Da estrutura prática à conjuntura interactiva: relendo o esboço de uma teoria da prática de Pierre Bourdieu. Revista Crítica de Ciências Sociais, n.64, p. 135-143, 2002. 
- A cultura profissional dos professores. $\mathrm{O}$ uso do conhecimento em contexto de trabalho na conjuntura da reforma educativa nos anos 90. Porto: Fundação Calouste Gulbenkian. Fundação para a Ciência e a Tecnologia, 2000.

COLLINS, H. Tacit and explicit knowledge. Chicago: The University of Chicago Press, 2010.

COUTER, J. Mind in action. Cambridge: Polity Press, 1989.

DODIER, N. Les appuis conventionnels de l'action. Elements de pragmatique sociologique. Réseaux. Communication - Technologie - Société, Volume 11, Numéro 62. p. 63 - 85, 1993. Disponível em: http://www.persee.fr. Acesso em: 19 nov. 2014.

ERAUT M.; HIRSH, W. The Significance of Workplace Learning for Individuals, Groups and Organisations. New York: ESRC Centre on Skills, Knowledge and Organisational Performance, 2007.

EVANS, J. Dual-Processing accounts of reasoning, judgment, and social cognition. Annu. Rev. Psychol, 59:255-78, 2008.

How many dual-process theories do we need? One, two, or many? In: EVANS, J.; FRANSKISH, K. In two minds: dual processes and beyond. New York: Oxford Press, 2009. p. 33-54.

FILIPE, J. M. Nós: do encontro de experiência à construção de um saber de referência para a coordenação da acção conjunta - uma voz para os educadores, 339 f. Tese (Doutorado). Universidade de Lisboa. Faculdade de Ciências. Departamento de Educação. Sociologia da Educação. Volume IV. Anexos. Nós: história de uma equipa de educação especial. Lisboa: 2008.

GIDDENS, A. Dualidade da Estrutura: agência e estrutura. Oeiras: Celta Editora, 2000.

GOFFMAN, E. Les cadres de l'expérience. Paris: Lés edition de minuit, 1991.

GRAMSCI, A. Os intelectuais e a organização da cultura. Rio de Janeiro: Civilização Brasileira, 1991 a.

Concepşão Dialética da História. Rio de Janeiro: Civilização Brasileira, 1991b.

GRANJA, B. Identidade e saber dos Assistentes Sociais. Tese (Doutorado). Universidade do Porto. Instituto de Ciências Biomédicas. Porto, 2008.

KOSIK, K. Dialética do concreto. Rio de Janeiro: Paz e Terra, 1976.

LIMA, R. O marxismo e a pesquisa qualitativa como referências para investigação sobre educação profissional. In: LIMA, R.; RODRIGUES, D. A pesquisa em trabalho, educação e politicas educacionais. Campinas: Alínea, 2012. p. 157-184.

MINAYO, M. C. Ciência, Técnica e Arte: o desafio da pesquisa social. In: MINAYO, M. C. (org.). Pesquisa Social: teoria, método e criatividade. Petrópolis: Vozes, 1994.

NEVES, T. Entre educativo e penitenciário. Etnografia de um centro de internamento de menores delinquentes. Porto: Edições Afrontamento, 2008.

OGIEN, A. Émergence et contrine. Situacion et experience chez Dewey et Goffman. In: QUÉRÉ, L.; FORNEL, M. La logique des situations. Paris: École des Hautes Études em Siences Sociales, 1999. p. 69-93.

OGIEN, R. L’Idiot de Garfinkel. Le programme de l'ethnométhodologie. In: FORNEL, M.; OGIEN, A.; QUÉRÉ, L. L'ethnométhodologie. Une sociologie radicale. Paris: La Découverte, 2001. p. 57-74.

QUÉRÉ, L.; FORNEL, M. La logique des situations. Paris: École des Hautes Études em Siences Sociales, 1999. 
; SCHOCH, C. The still - neglected situation? Réseaux, 1998, vol. 6, n. 2, p. 223-253.

RAMOS, M. Trabalho, educação e correntes pedagógicas no Brasil: um estudo a partir da formação dos trabalhadores técnicos da saúde. Rio de Janeiro: EDUFRJ e EPSJV/Fiocruz, 2010.

REY, F. Pesquisa qualitativa em psicologia: caminhos e desafios. São Paulo: Pioneira, 2002.

TARDIF, M. Saberes profissionais dos professores e conhecimentos universitários. Elementos para uma epistemologia da prática profissional dos professores e suas consequências em relação à formação para o magistério. Revista Brasileira de Educação. Jan/Fev/Mar/Abr, 2000, n. 13. Disponível em: <http://educa.fcc.org. br/pdf/rbedu/n13/n13a02.pdf>. Acesso em:19 nov. 2014.

THOMPSON, E. Os românticos. Rio de Janeiro: Civilização Brasileira, 2002.

Costumes em comum. Estudos sobre a cultura popular tradicional. Rio de Janeiro: Companhia das Letras, 1998.

- A formação da classe operária inglesa. Rio de Janeiro: Paz e Terra, 1998.

- A miséria da teoria ou um planetário de erros, uma crítica ao pensamento de Althusser.

Rio de Janeiro: Zahar Editores, 1981.

\section{NOTAS}

${ }^{1}$ Situamos na abordagem sociointeracionista o interacionismo simbólico de Mead e Blummer e a teoria da teatralização social de Goffman. Em ambas, a realidade social é produto das ações humanas numa rede de intersubjetividade, resultado de ações dirigidas para o outro e que adquire significado sempre negociado e compartilhado com o outro, face às expectativas mútuas. Porém, se no primeiro a interação é sempre uma negociação simbólica, no segundo ela é também manipulação.

${ }^{2}$ Conhecimentos científicos, tecnológicos e filosóficos são designados na literatura, por vezes como conhecimento proposicional (Couter, 1989; Collins, 2010), como conhecimento codificado (Eraut, 2007), ou como conhecimento abstrato Caria (2012). Nesse texto, optamos por designá-los genericamente como conhecimentos científicos.

${ }^{3}$ LEVY, A. La recherche-action - une autre voie pour les sciences humanines? In: BOUTINET, J. (org.). Du discours à l'action - les science sociales s'interrogent sur ellesmêmes. Paris: L'Harmattan. p. 50-68.

Recebido: $24 / 04 / 2013$

Aprovado: 21/08/2014

Contato:

Programa de Pós-Graduação em Educação Profissional em Saúde Escola Politécnica de Saúde Joaquim Venâncio Fundação Oswaldo Cruz Av. Brasil, 4365 Manguinhos Rio de Janeiro | RJ | Brasil

CEP 21.040-900 
